\title{
Rainfall threshold for hillslope outflow: an emergent property of flow pathway connectivity
}

\author{
P. Lehmann ${ }^{1,2, *}$, C. Hinz ${ }^{2}$, G. McGrath ${ }^{2}$, H. J. Tromp-van Meerveld ${ }^{3,4}$, and J. J. McDonnell ${ }^{5, * *}$ \\ ${ }^{1}$ Institute of Terrestrial Ecology, Swiss Federal Institute of Technology, ETH Zurich, Switzerland \\ ${ }^{2}$ School of Earth and Geographical Sciences, The University of Western Australia, Crawley, Australia \\ ${ }^{3}$ Simon Fraser University, Department of Geography, Burnaby BC, Canada \\ ${ }^{4}$ School of Architecture, Civil and Environmental Engineering, EPFL Lausanne, Switzerland \\ ${ }^{5}$ Water Resources Section, Delft University of Technology, Delft, The Netherlands \\ *now at: Laboratory of Soil and Environmental Physics, EPF Lausanne, Switzerland \\ *** on leave from: Dept. of Forest Engineering, Oregon State University, Corvallis, USA
}

Received: 14 July 2006 - Published in Hydrol. Earth Syst. Sci. Discuss.: 20 September 2006

Revised: 15 February 2007 - Accepted: 14 March 2007 - Published: 2 April 2007

\begin{abstract}
Nonlinear relations between rain input and hillslope outflow are common observations in hillslope hydrology field studies. In this paper we use percolation theory to model the threshold relationship between rainfall amount and outflow and show that this nonlinear relationship may arise from simple linear processes at the smaller scale. When the rainfall amount exceeds a threshold value, the underlying elements become connected and water flows out of the base of the hillslope. The percolation approach shows how random variations in storage capacity and connectivity at the small spatial scale cause a threshold relationship between rainstorm amount and hillslope outflow.

As a test case, we applied percolation theory to the well characterized experimental hillslope at the Panola Mountain Research Watershed. Analysing the measured rainstorm events and the subsurface stormflow with percolation theory, we could determine the effect of bedrock permeability, spatial distribution of soil properties and initial water content within the hillslope. The measured variation in the relationship between rainstorm amount and subsurface flow could be reproduced by modelling the initial moisture deficit, the loss of free water to the bedrock, the limited size of the system and the connectivity that is a function of bedrock topography and existence of macropores. The values of the model parameters were in agreement with measured values of soil depth distribution and water saturation.
\end{abstract}

Correspondence to: P. Lehmann

(peter.lehmann@epfl.ch)

\section{Introduction}

Rainfall-induced subsurface stormflow at the hillslope scale is a dominant outflow process in many steep, humid watersheds (Bonell, 1998; Weiler et al., 2005). Nevertheless, the exact nature of subsurface stormflow is very difficult to discern in ungauged watersheds, depending largely on hydraulic conductivity of the vadoze zone, the permeability of the underlying bedrock, existence of soil layers and macropores, soil depth and the local slope angle. Based on these complex interrelations, the relationship between rainfall and hillslope outflow is difficult to predict. Despite these local controls, distinct threshold behaviour has also been observed. For example, Whipkey (1965) found for a field experiment in Ohio, USA, a precipitation threshold of $35 \mathrm{~mm}$ and an increase in flow with a slope (increase of runoff per increase of rainfall amount) less than 1.0 for higher rainstorm amounts. Mosley (1979) showed a linear increase with slope close to 1.0 for rainfall amounts higher than $20 \mathrm{~mm}$ for a field site near Reefton in New Zealand. For smaller precipitation amounts, no flow was detected. The storm outflow measured by Tani (1997) at a trench site near Okayama in Japan was almost zero for precipitation amounts smaller than $20 \mathrm{~mm}$. At a trench site in Georgia, USA, Tromp-van Meerveld and McDonnell (2006a) observed a threshold value of $55 \mathrm{~mm}$ of rainfall.

While the precise value of the threshold and the nature of the relationship between rainfall and subsurface stormflow for storms larger than the threshold are different, the

Published by Copernicus GmbH on behalf of the European Geosciences Union. 


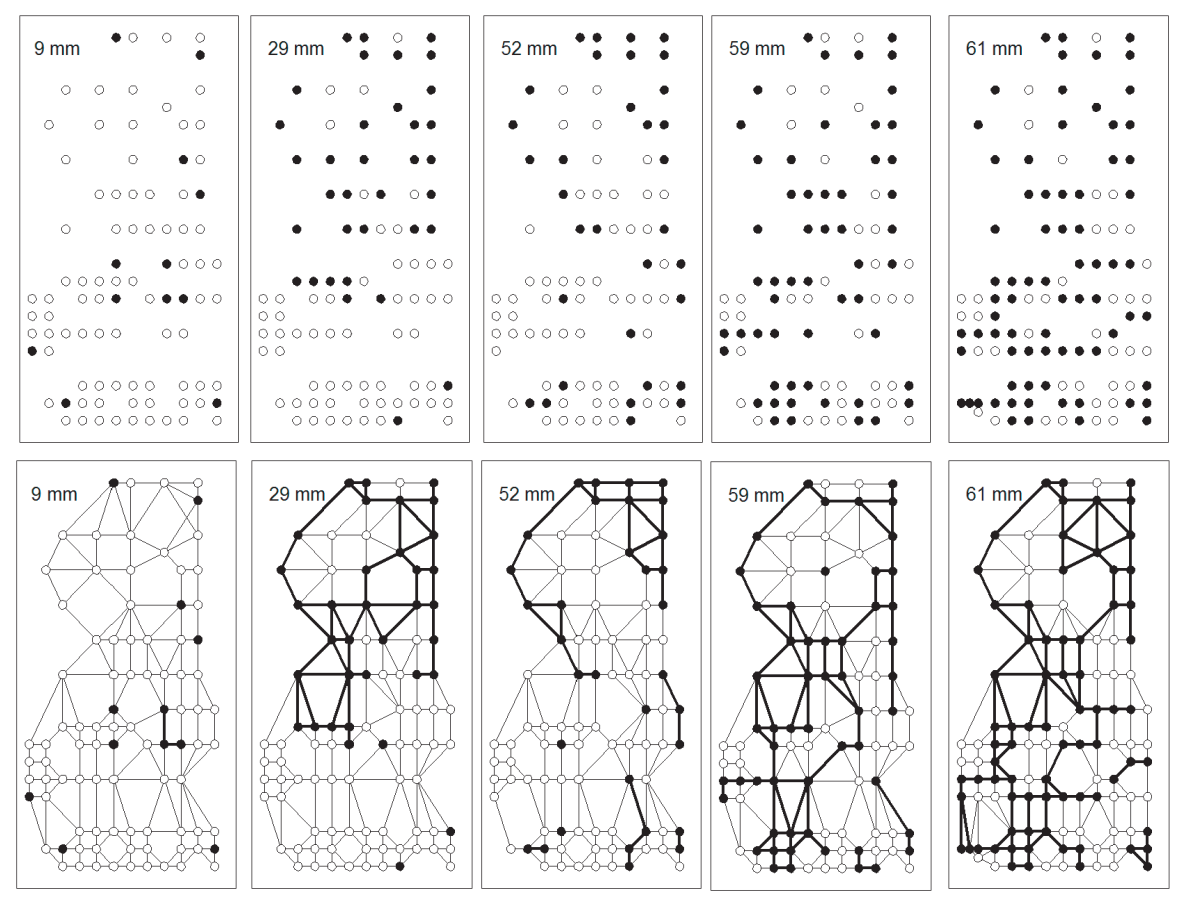

Fig. 1. Patterns of transient saturation as a function of rainstorm amount measured at Panola (Georgia, USA). Locations of piezometers with a water table during the rainstorm event are shown with black disks; dry sites are shown with open circles. In the bottom row, a grid connecting the sites is shown for visualization purposes. For each site the nearest neighbors in four directions (above, below, to the right, to the left) were determined. Thick lines connect two sites with free water. For 59 and $61 \mathrm{~mm}$ of rainstorm amount, a network of connections between sites with free water spans the whole system.

existence of a threshold relationship between rainfall amount and fast lateral hillslope outflow appears to be a common property of hillslope drainage (Weiler et al., 2005). While the threshold may be easily explained by a simple bucket model based on a limited water storage capacity, such a description would be too simple because the threshold depends not on a mean value but on the heterogeneity of the hillslope and the arrangement of zones with different properties. The relation between hillslope wetting pattern and the threshold subsurface stormflow process needs to be better understood to predict the outflow from hillslopes or catchments, particularly in ungauged settings. Tromp-van Meerveld and McDonnell (2006b) presented the fill and spill hypothesis to explain the threshold, assuming that water flows from upslope positions to lower sections of the hillslope following the subsurface topography. They based their hypothesis on measured spatial and temporal patterns of saturation at the soil bedrock interface. Their results showed that while a water table developed on parts of the hillslope during events smaller than the threshold, it was not until bedrock depressions on the hillslope were filled, water spilled over micro-topographic relief in the bedrock surface and the subsurface saturated areas became connected to the trench that significant subsurface flow occurred. When connectivity was achieved, the instantaneous subsurface stormflow rate increased more than five fold compared to before the subsurface saturated areas were connected to the trench face. Similarly, Spence and Woo (2003) found for a soil filled valley on the subarctic Canadian shield that spatially variable valley storage had to be satisfied before water spilled to generate either surface or subsurface flow. Western et al. (2001) showed that the degree of connectivity of soil moisture patterns was relevant for the downhill flow of saturation excess runoff. Furthermore, Sidle et al. (2001) described observed hillslope outflow as the emergence of a continuous macropore network which developed during storms and seasonally as the hillslope wetted up. In summary macroscopically observed rainfall thresholds for an entire hillslope seem to be related to the flow path connectivity at the next smaller spatial scale. We therefore refer to this threshold as an emergent system property that needs further research.

In this study we examine how subsurface connectivity is related to the observed rainfall thresholds triggering rapid hillslope outflow. We hypothesize that after rainstorm events the water flows along preferential flow pathways which may include macropores, bedrock valleys, and free water ponding at the bedrock. As long as these pathways are not connected the runoff at the bottom of the hillslope will be small but increases dramatically if the flow pathways become connected. Percolation theory, which predicts threshold relationships in 
connectivity (Stauffer and Aharony, 1994), provides a way forward in predicting the pattern - process linkage at the hillslope scale. The data of Tromp-van Meerveld and McDonnell (2006b) with the spatial distribution and connectedness of adjacent wet cells appears to follow regular rules of connectivity (Fig. 1). These rules, derived from field observations, appear very much in line with percolation theory. Percolation theory describes the statistical properties of a system containing an infinite number of elements, denoted as sites, arranged on a regular grid. For each site only two states, denoted as occupied or non-occupied, are possible. The spatial properties of clusters with occupied sites and threshold relationship for the occurrence of a cluster that connect the whole system can be deduced with percolation theory (Stauffer and Aharony, 1994; Sahimi, 1994; Essam, 1980). This simple framework appears highly relevant to recent observations at Panola and elsewhere in the hillslope hydrological literature (Uchida et al., 2005). This paper uses tools from percolation theory to characterize connectivity and how this might relate to rainfall thresholds controlling hillslope scale subsurface flow.

Our analyses presented in this paper are based upon the following underlying process assumptions:

(i) Water flows laterally only through soil sites with a water table. This means that the soil close to the bedrock becomes water saturated during a rainstorm event and only this free water can flow downslope. Therefore, the soil elements can only be in two states, wet and dry or, equivalently, occupied or non-occupied with free water. This simplification is in keeping with recent observations of the fill and spill hypothesis (Spence and Woo, 2003).

(ii) The initial water deficit in the soil is important for subsurface flow initiation. The responses for initially wet and dry systems are different. Tromp-van Meerveld and McDonnell (2006b) found limited lateral hillslope outflow when the bedrock depressions were not water filled. Antecedent moisture conditions at depth and total precipitation amount determine whether or not significant flow $(>1 \mathrm{~mm})$ occurs (Tromp-van Meerveld and McDonnell, 2006a).

(iii) Water flow in the down slope direction is affected by bedrock topography. For instance, water can not flow along the bedrock if the elevation of the bedrock increases in down slope direction.

(iv) Soil pipes or macropores enhance lateral flow when the connectedness of subsurface saturation is achieved. Exchange of water between the soil matrix and preferential flow paths may occur in small isolated zones in the profile (and in the hillslope) and do not require complete soil column mixing (Uchida et al., 1999).

(v) The factors influencing subsurface stormflow initiation (initial soil water content, soil depth or macropore presence) are randomly distributed. This assumption follows recent physically based modelling studies of Weiler et al. (2003) where model realizations enlightened the effect of random soil pipe distribution on the estimated outflow. In addition, the state of one soil element is independent of the state of neighbouring soil elements corresponding to a random field without spatial correlation. This assumption appears justified by observations of the high spatial variability of occurrence of a water table (Tromp-van Meerveld and McDonnell, 2006b), and the dominance of lateral preferential flow pathways in steep hillslopes (Kirkby, 1988).

Based on these assumptions, we will use percolation theory to model subsurface hillslope outflow. Firstly, core concepts of percolation theory are introduced followed by a definition of how we relate the element scale water balance to those concepts adopted from the theory. We explore the influence of connectivity, moisture deficit and bedrock permeability on the threshold behavior of the modeled subsurface outflow. We will discuss the model that gives an optimized description of the relationship between rainfall and runoff. In a first step, we will focus on the average relationship neglecting the measured variation in the subsurface flow. However, the measured variations of runoff response can be very high for different conditions and a model must capture these features as well. In a second step, we will analyze the model parameters that affect the variability of the computed runoff. For that purpose, the system size, rainfall intensity and the initial water content are taken into account. We apply percolation theory to model hillslope outflow measured at the Panola trench site which is described in detail in Freer et al. (1997, 2002), Burns et al. (1998) and Tromp-van Meerveld and McDonnell (2006a, b).

\section{Percolation theory as applied to hillslope hydrology}

In the following we review the core concepts of percolation theory as it applies here to our description of hillslope outflow. For a more general application of percolation theory in hydrology and soil science we refer to Berkowitz and Balberg (1993), Berkowitz and Ewing (1998) and Hunt (2005). All variables of the percolation model are listed in Table 1.

\subsection{Connectivity and occupation probability}

The hillslope is represented as a grid of sites that form a lattice connected by bonds. For each element (site) in our hillslope lattice, only two states, denoted as occupied or nonoccupied, are possible. The sites of the lattice are connected by bonds. The number of connections per site is defined as the coordination number $n$ and is four or eight in case of the orthogonal lattice. In the percolation model of the hillslope, an occupied site is a location with a transient water table at the soil bedrock. The bond may be interpreted as a fast flow pathway such as a macropore, a soil volume with a high hydraulic conductivity or as a configuration of the bedrock topography that allows water to flow in down slope direction along the bedrock valleys. Two occupied and connected sites are conducting with respect to subsurface flow. In a hillslope, 
Table 1. Summary of parameters used in percolation model.

\begin{tabular}{|c|c|c|c|c|}
\hline symbol & Name & units & value (most frequent) & values (range) \\
\hline$A$ & cross sectional area of soil site & $\mathrm{m}^{2}$ & 1 & $0.04-25$ \\
\hline$b$ & fractional loss of free water to the bedrock & - & 0.65 & $0.00-0.80$ \\
\hline$c, c_{i}$ & water storage capacity of site $i$ & $\mathrm{~mm}$ & & $0-300$ \\
\hline$d$ & soil depth & $\mathrm{m}$ & 0.609 & $0.0-1.86$ \\
\hline$F(p)$ & fraction of drainable sites & - & & $0.0-1.0$ \\
\hline$L_{x} \times L_{y}$ & number of grid points along the slope $\left(L_{x}\right)$ and in upslope direction $\left(L_{y}\right)$ & - & $20 \times 50$ & $4-500$ \\
\hline$n$ & coordination number & - & 3.2 & $1.6-8.0$ \\
\hline$N$ & number of occupied sites connected to the lower boundary & - & & $0-250000$ \\
\hline$N(p)$ & fraction of occupied sites & - & & $0.0-1.0$ \\
\hline$p$ & occupation probability & - & & $0.0-1.0$ \\
\hline$p_{c}$ & percolation threshold & - & & $0.4-1.0$ \\
\hline$P(p)$ & fraction of realizations with a percolation cluster & - & & $0.0-1.0$ \\
\hline$r$ & rainstorm amount & $\mathrm{mm}$ & & $0.0-154$ \\
\hline$r_{c}$ & threshold rainstorm amount & $\mathrm{mm}$ & 46 & $46-47.5$ \\
\hline$x$ & random number & - & & $0.0-1.0$ \\
\hline$\Delta x$ & distance between grid points & $\mathrm{m}$ & 1 & $0.2-5$ \\
\hline$\mu$ & mean storage capacity of percolation network & $\mathrm{mm}$ & 30 & $20-60$ \\
\hline$\mu(\theta)$ & mean of storage capacity for initial water content $\theta$ & $\mathrm{mm}$ & & $23-85$ \\
\hline$\mu_{d}$ & mean soil depth & $\mathrm{m}$ & 0.609 & \\
\hline$\sigma$ & standard deviation of storage capacity & $\mathrm{mm}$ & 17.5 & \\
\hline$\sigma(\theta)$ & standard deviation of storage capacity for initial water content $\theta$ & $\mathrm{mm}$ & & $14-50$ \\
\hline$\sigma_{d}$ & standard deviation of soil depth & $\mathrm{m}$ & 0.358 & \\
\hline$\theta$ & volumetric water content & $\mathrm{m}^{3} \mathrm{~m}^{-3}$ & & $0.311-0.413$ \\
\hline$\theta_{w}$ & volumetric water content for 68 events with wet initial conditions & $\mathrm{m}^{3} \mathrm{~m}^{-3}$ & 0.402 & $0.392-0.413$ \\
\hline$\theta_{c}$ & threshold volumetric water content for free water & $\mathrm{m}^{3} \mathrm{~m}^{-3}$ & 0.451 & \\
\hline
\end{tabular}

the number of bonds is not a constant in space and can differ from the values of 4,8 or 6 of the orthogonal or hexagonal lattice, respectively. To generate lattices with other coordination numbers, some connections of an original lattice with 8 neighbours per site were destroyed in a random process. For that purpose, a random number $x$ between 0.0 and 1.0 was allocated to each connection. The bond remains if $x \leq(n / 8.0)$, resulting in a lattice with coordination numbers between 0 and 8.0. The coordination number is not the same for all sites and the average of the coordination number of all sites can be real valued. Figure 2 shows an example of a lattice with a fractional coordination number of $n=4.8$.

In percolation theory the state (occupied or non-occupied) of an element is assigned by a random process (Broadbent and Hammersley, 1957). In the hillslope, the state of a site depends on the real hydrological processes and is not the result of a random process but depends on soil depth, initial state, porosity, hydraulic conductivity and its location relative to other occupied sites. But we assume that these processes cause a random distribution of sites with or without transient water saturation.

The occupation probability $p$ determines the fraction of occupied nodes $N(p)$. Technically, a random distribution of sites according to a certain occupation probability can be generated with two different methods (Stauffer and Aharony,
1994). With the first method, the coordinates of $p \times L_{x} \times L_{y}$ sites are determined in a random process with the number of sites in horizontal $\left(L_{x}\right)$ and vertical direction $\left(L_{y}\right)$. With this method, the fraction of occupied sites $N(p)$ equals the occupation probability $p$. We used a second approach by choosing a random number $x$ between 0.0 and 1.0 that is allocated to each site. These random numbers are compared to the value $p$ of the occupation probability. If $x \leq p$, the element is occupied. The higher the value of $p$, the more elements are occupied. In Fig. 2, the resulting distributions of occupied and non-occupied sites are shown for different values of $p$. For infinite systems, the fraction of occupied elements using this second approach equals the occupation probability $p$. For systems of finite size, the realized fraction of occupied sites may deviate slightly from the value $p$.

\subsection{Percolation threshold}

Occupied sites connected by a bond form a cluster. With increasing occupation probability $p$, an increasing number of occupied elements are connected and the clusters grow. For a certain occupation probability $p \geq p_{c}$, a cluster that spans the whole system, the percolation cluster, exists. This value $p_{c}$ is denoted as the percolation threshold. In Fig. 2, a percolating cluster emerges for $p \geq 0.6$. Conceptually, this is analogous 
to the connectedness of subsurface flowpaths in natural systems (e.g. Tromp-van Meerveld and McDonnell, 2006b). As long as this threshold is not reached, only a minor portion of the occupied sites can be drained to the trench. These sites are closed to the bottom of the hillslope and no occupied sites from the upper part of the hillslope can drain. For an infinite system, the percolation threshold is well defined and a percolating cluster never exists for occupation probabilities $p<p_{c}$ and will always exist for $p>p_{c}$. In the case of a finite system, it is possible that a percolating cluster exists for $p<p_{c}$ or does not exist for $p>p_{c}$, depending on the realized spatial distribution of occupied elements. In addition, the value for the percolation threshold itself depends on the lattice size and converges to the value for infinite systems with increasing lattice size. As shown in Fig. 1, the system under investigation has been experimentally characterized by a relatively small number of observations. Accordingly, one aspect of this paper is to determine the threshold relationship in finite systems. To analyse the percolation threshold for systems of finite size, a certain number of realizations of a system with an occupation probability $p$ are generated and the fraction $P(p)$ of realizations with a percolation cluster are counted. The fraction $P(p)$ for systems with different coordination numbers are shown in Fig. 3. For lattices with a high coordination number $n$, the percolation threshold is low and a small fraction of full sites is needed to form a system spanning cluster. Close to the percolation threshold, the fraction $P(p)$ changes from 0 to 1 . This is shown in Fig. 3 for an occupation probability of about 0.465 and 0.720 for a coordination number of 6.4 and 3.2 , respectively.

\subsection{Relevant cluster size}

The size of a cluster is defined as the number of occupied sites that are interconnected. With respect to outflow from a hillslope, only the clusters that are connected to the lower boundary can contribute to the outflow. We define the fraction of drainable sites (occupied and connected to the lower boundary) as $F(p)$. With increasing occupation probability $p$, more occupied sites are connected to the boundary. For small occupation probabilities $p<p_{c}$, only the sites close to the lower boundary are connected and can be drained. The probability to find a percolation cluster $P(p)$ and the drainable fraction $F(p)$ are shown in Fig. 3 as a function of coordination number, for 100 realizations of a system containing $500 \times 500$ sites. For an occupation probability close to the percolation threshold, the fraction of drainable sites increases because a system spanning cluster exists. This increase of drainable sites for occupation probabilities close to the threshold is the most relevant characteristic for the modelled runoff. While the occupation probability increases linearly from 0 to 1.0 , the increase of number of sites connected to the trench is highly non-linear and is most pronounced at the percolation threshold. For higher occupation probabilities, more sites become connected to the percolation cluster

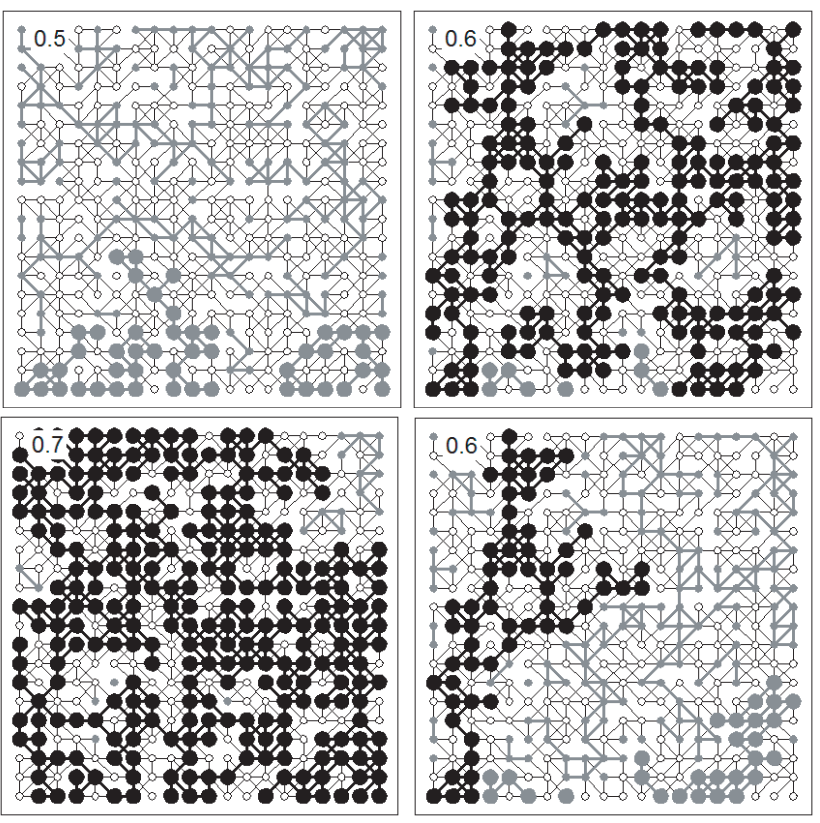

Fig. 2. The effect of occupation probability $p$, indicated by the numbers in the left upper corner. Non-occupied sites are shown with small open circles. Occupied sites belonging to the percolation cluster are drawn in black. Occupied sites in gray are not elements of the system spanning cluster. Occupied sites that are connected to the bottom of the system are indicated with large disks. These sites contribute to the hillslope outflow. In the right figure in the bottom row, the connections between occupied sites are modified by the condition that flow cannot occur in upward direction. In that case, less water will drain out to a trench at the bottom line. The underlying grid has a coordination number of 4.8 .

and the drainable fraction increases monotonically. If the coordination number is high enough, all sites are connected to the lower boundary for $p=1.0$. For small coordination numbers some sites may not be connected to the percolation cluster and do not drain out. In Fig. 3, 2.2\% of occupied sites are not connected to the percolation cluster for $n=3.2$. As a further requirement for modelling hillslope processes, water cannot flow in upslope direction due to gravitational forces and these bonds do not contribute to the outflow. The effect of this limitation is shown in Figs. 2 and 3. In the network shown in Fig. 2 less sites drain out and the cluster spans the system only along the slope. Due to the fact that not all connections between occupied sites contribute to a connection between the top and the bottom of the system, more sites must be occupied to build a percolation cluster. In Fig. 3, the percolation threshold for a lattice with coordination number 6.4 increases from 0.465 to 0.520 and from 0.720 to 0.825 in case of a coordination number of $n=3.2$. In the latter case, only $85 \%$ of the occupied sites contribute to the outflow for $p=1$. The remaining $15 \%$ are smaller clusters that are not connected to the percolation cluster. 


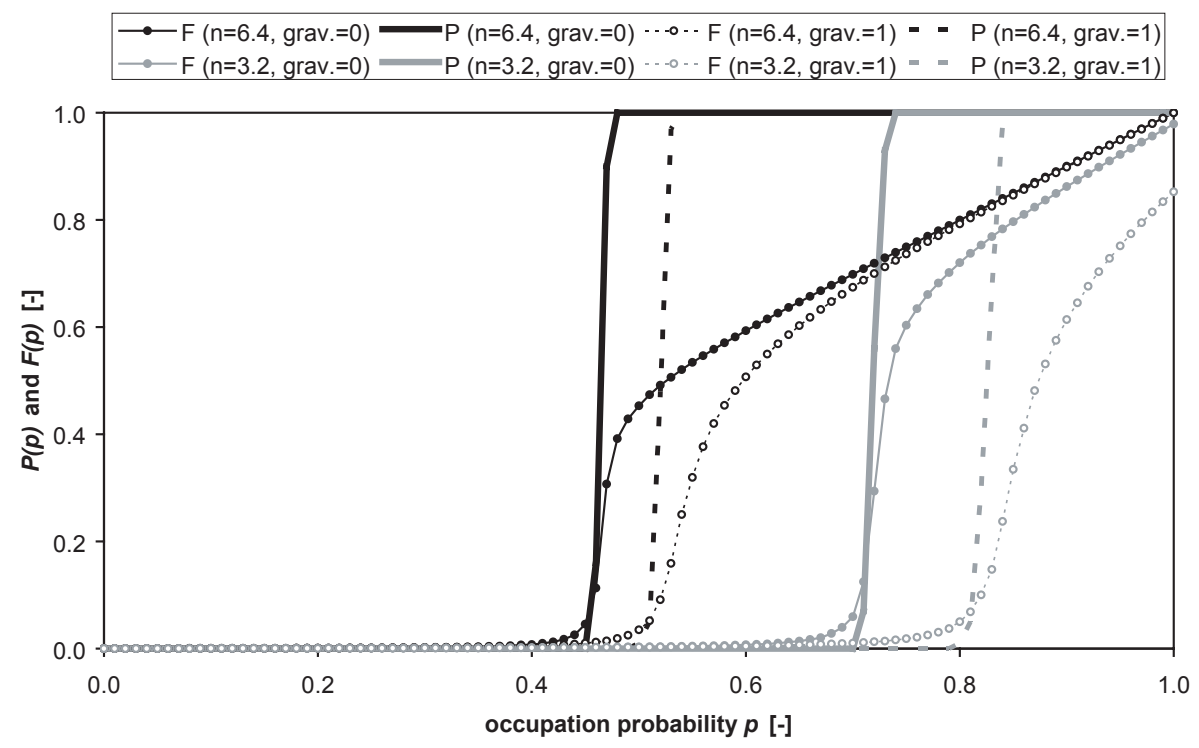

Fig. 3. The fraction $P$ of realizations with a percolation cluster (lines without symbols) and the fraction $F$ of occupied sites connected to the bottom of the system (lines with symbols) as a function of occupation probability $p$. At the percolation threshold a cluster spanning the whole system emerges and the fraction $P$ changes from 0 to 1 . At this threshold, the fraction of drainable sites $F$ increases corresponding to an enhanced outflow at the trench of the hillslope. With decreasing connectivity of the lattice, indicated by the small coordination number $n$, more sites must be occupied to build a connected system. The dashed lines indicate the results of a model that takes into account that water can not flow in upward direction against gravitational forces. In the legend, this is indicated by the notation grav. $=1$ (grav. $=0$ otherwise). The results were calculated for 100 realizations of systems containing $500 \times 500$ sites.

\section{Hydrology of a hypothetical hillslope}

In this section, percolation model parameters are related to hydrological properties of hillslope systems. In particular, we define how sites become connected based on rainfall and drainage into the bedrock. For later comparison, the results measured at Panola are also shown in the corresponding figures. First, we will introduce the model parameters and then we will show their effects on modelled outflow after a rainstorm event.

\subsection{Methodology}

\subsubsection{Storage capacity distribution}

A soil site must receive a certain volume of rainfall water before a water table emerges and the free water can flow downwards driven by gravity. In the percolation model, a site with a water table is denoted as occupied. The maximum water volume that can be stored before a free water table emerges can be denoted as field capacity. In the percolation model, a site with a small capacity (i.e. a small moisture deficit) is close to field capacity and only a small amount of rainfall is required before free water develops. We denote the volume of water deficit, divided by the cross-section of a soil site $A$ as the available storage capacity $c[\mathrm{~mm}]$. The capacity depends on initial soil moisture, field capacity and soil depth. Based on measurements of the soil depth distribution
(Freer et al., 1997) and soil moisture measurements (Trompvan Meerveld and McDonnell, 2006c) at Panola, we assume that the superposition of the spatial distribution of these different properties results in a normal distribution of the capacity values $c_{i}$ with a mean value $\mu$ and a standard deviation $\sigma$. Computationally the storage capacity at site $i\left(c_{i}\right)$ is assigned randomly by generating a uniformly distributed random number $x$ between 0 and 1 and solving for $c_{i}$ from the integral of the normal distribution (i.e. the error function erf):

$x=\frac{1}{2}+\frac{1}{2} \operatorname{erf}\left[\frac{c_{i}-\mu}{\sigma \sqrt{2}}\right]$.

Additionally we ensure $c_{i}=\max \left[0, c_{i}\right]$, i.e. we truncate the normal distribution in order to avoid physically meaningless values of $c_{i}$. This also allows us to describe a portion of the hillslope as exposed bedrock, which is the case at Panola (Freer et al., 2002). The rainfall divided by the cross-section of a soil site $A$ is denoted as rainstorm amount $r[\mathrm{~mm}]$ or rainfall depth. If the rainfall amount is higher than the storage capacity at a certain site $c_{i}$, a water column of height $r-c_{i}$ is available for subsurface flow. Figure 4 illustrates this conceptually. For a certain rainstorm amount, a fraction of sites will be occupied depending on the distribution of the storage capacities $c_{i}$. The higher the rainfall amount, the more sites are occupied and have a water table. 


\subsubsection{Outflow}

For large rainfall amounts, the additional water cannot be stored and is free to drain out. If $r>c_{i}$, the site $i$ is occupied and the excessive water $r-c_{i}$ is drainable. For a system with $L_{x} \times L_{y}$ sites, the rainstorm volume is $\operatorname{Ar}\left(L_{x} \times L_{y}\right)$ and the outflow is the excessive water in the open sites connected to the lower boundary, given by

$$
A \sum_{i=1}^{i=N}\left(r-c_{i}\right)
$$

with the number of occupied sites connected to the lower boundary $N$. This sum divided by the total area of the system $A\left(L_{x} \times L_{y}\right)$ is defined as modelled subsurface outflow.

\subsubsection{Deep drainage through bedrock}

As described in the introduction, the observed runoff coefficient after the threshold was in some cases smaller than 1.0. This can be explained by losses of free water to bedrock or evaporation, root intake and interception. If the soil is wet and free water is available, the water can percolate into the underlying bedrock. The amount of water dripping into the bedrock depends on the hydraulic conductivity of the bedrock and the pressure head. Here, we simplify the description of water loss by defining a dimensionless draining fraction $b[-]$ ranging from 0.0 (no deep drainage) to 1.0 (all free water lost to the bedrock). For rainstorm amounts larger than the capacity $c_{i}$ at site $i$, an amount $b A\left(r-c_{i}\right)$ was assumed to be lost or drained into the underlying bedrock. Later on, we will take into account that the fraction $b$ may change with intensity. For high rainfall intensity, water can flow rapidly to other occupied cells and into the trench before it could percolate into the bedrock. A flow of water through the bedrock towards other soil sites is not included.

\subsubsection{Systems of finite size}

For a system with few sites, the modeled outcome is very sensitive to the position of the occupied and non-occupied sites. Therefore, the results will depend on the limited size of the system. The real geometry is subdivided into a grid with $L_{x} \times L_{y}$ sites. The distance between grid points denoted as $\Delta x[\mathrm{~m}]$ corresponds to a real length. Each site represents a cross-section of $A\left[\mathrm{~m}^{2}\right]$ that is equal to $(\Delta x)^{2}$ in case of an orthogonal lattice. To represent the average of a system of limited size, several realizations of a system for each occupation probability $p$ are generated and analysed.

\subsubsection{Modeling}

For each realization of the system, a certain fraction of bonds is destroyed in a random process to obtain the desired coordination number. For each realization of the network of bonds, the rainstorm amount is increased in intervals of $0.05 \sigma$ between $\mu-5 \sigma$ (or 0 ) and $\mu+10 \sigma$. For each site and for each
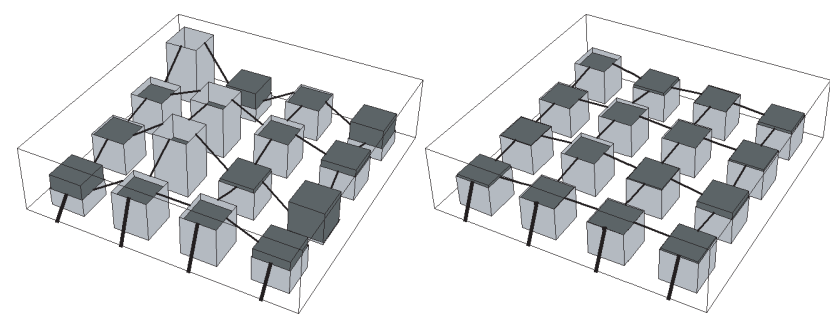

Fig. 4. Model principles to describe hillslope outflow. Each site has a storage capacity to retain water. In the left figure, the capacity values $c$ of the sites are random numbers between 0.0 and 1.0 and are shown in light gray. All sites received the same amount of water $r$ during the storm (dark gray boxes). In this example, $r$ equals 0.5 . The volume of the water above the capacity value corresponds to the water that can drain out if it is connected to the boundary at the bottom. In this example, six sites have free water that is hydraulically connected to the lower boundary of the system. In one case (top row), a site with free water is enclosed by unsaturated sites. Right: In this model, the capacity values are distributed according to a normal distribution with mean 0.5 and a standard deviation of 0.05 .

rainstorm amount, a value of the storage capacity $c_{i}$ is determined randomly and is compared to the rainstorm amount $r$. Sites with $r>c_{i}$ are occupied with free water and a water amount of $(1-b) A\left(r-c_{i}\right)$ is drained to the trench if the site is connected to the lower boundary of the system. For each rainstorm amount, the average outflow of all realizations is computed.

\subsection{Model results}

In Fig. 5, the modelled outflow for different parameters of the percolation model is shown. The results show the average of 100 realizations of a system with $20 \times 50$ sites. For the Panola trench study with a field site of $20 \times 50 \mathrm{~m}$, the distance $\Delta x$ between two grid points corresponds to $1 \mathrm{~m}$. The results are compared to the outflow measured at Panola (see Sect. 4). The measurements can be reproduced with a percolation model with a distribution of the capacity values with a mean $\mu=30 \mathrm{~mm}$, a standard deviation $\sigma=17.6 \mathrm{~mm}$, a coordination number $n=3.2$ (60\% of all bonds are destroyed randomly) and a loss of free water to the bedrock of $b=65 \%$. For rainstorm between 40 and $80 \mathrm{~mm}$, a steep increase of the outflow can be observed that is followed by a linear increase for higher rainstorm amounts. As shown in Fig. 3, the percolation threshold for a coordination number of 3.2 is about $p_{c}=0.825$. For the capacity distribution function, this corresponds to a rainstorm amount of $r_{c}=46.5 \mathrm{~mm}$ to obtain a percolation threshold. For a doubled standard deviation of $\sigma=35 \mathrm{~mm}$, a higher rainstorm amount is required to obtain an occupation of about $82.5 \%$. The shift to higher rainstorm events to produce subsurface flow is more distinct for a storage capacity distribution with a doubled mean of $\mu=60 \mathrm{~mm}$. For a system with doubled coordination number $(n=6.4)$, less 


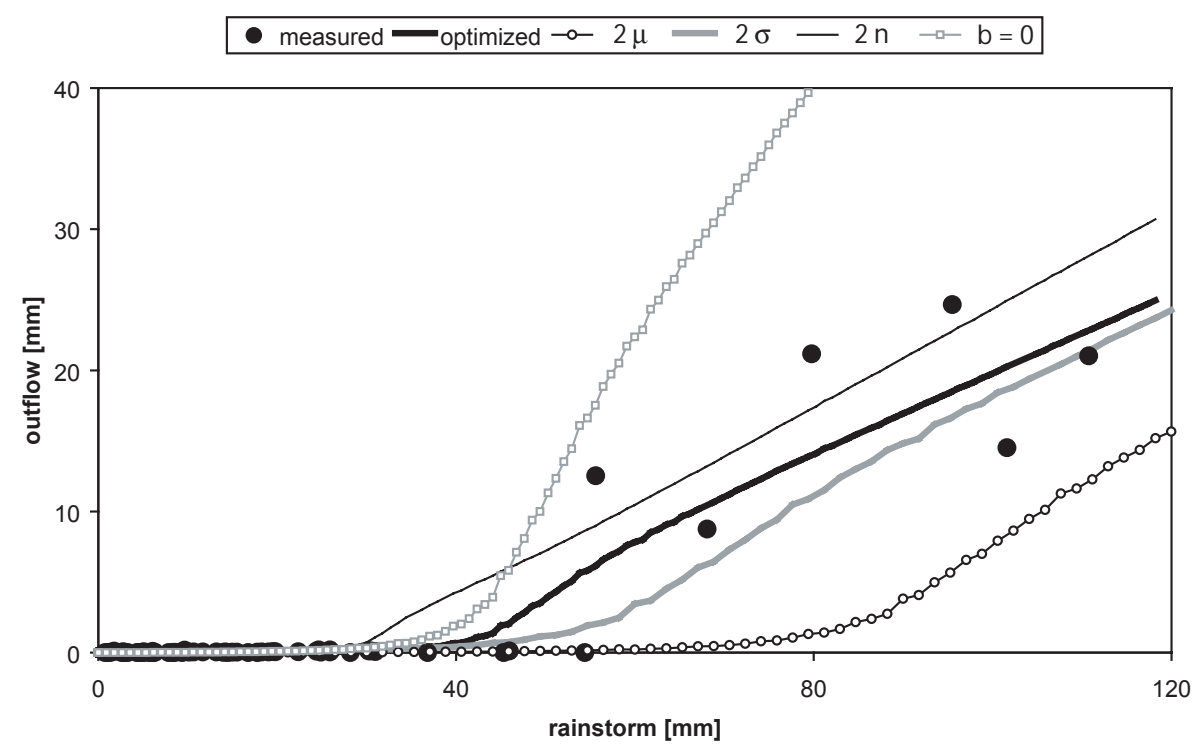

Fig. 5. Modelled outflow as a function of storage capacity. The bold black line was fitted to measurements (large symbols) with a mean $30 \mathrm{~mm}$, a standard deviation $17.6 \mathrm{~mm}$, a coordination number $n=3.2$ and a loss of free water of $b=65 \%$. The results are compared to a model with doubled mean (black line with symbols), doubled standard deviation (bold gray line), doubled coordination number (thin black line) and no loss of the free water (gray line with symbols). The averages of 100 realizations with a system of size $20 \times 50$ are shown.

occupied sites are needed to form large clusters connected to the lower boundary and the outflow increases for rainstorm amounts higher than $30 \mathrm{~mm}$. As shown in Fig. 3, the percolation threshold for a lattice with $n=6.4$ and the requirement of no flow occurring in upslope direction was about $50 \%\left(p_{c}=0.520\right)$. So, for a rainstorm amount of $30 \mathrm{~mm}$, the percolation threshold is reached and the outflow increases.

The effect of the loss to the bedrock is shown in Fig. 5 for systems with $b=0.65$ and $b=0.0$. While the outflow increases for rainstorm amounts higher than $40 \mathrm{~mm}$ in both cases, the increase of outflow with rainstorm amount $r$ is much steeper in case of no loss of free water.

Our analysis was done for various system sizes from larger systems with 25000 nodes $(100 \times 250$ with $\Delta x=0.2 \mathrm{~m}$ for Panola) to small systems with node numbers as low as 40 ( $4 \times 10$ with $\Delta x=5 \mathrm{~m}$ for Panola). In all cases, 100 realizations were analysed. In Fig. 6, the results as a function of system size are shown for $n=3.2$ and in one case for $n=6.4$ to show the effect of coordination number on the variation of modelled outflow. For small systems, the modelled outflow strongly depends on the arrangement of the occupied sites. Each of the few cells represents a large area of the hillslope and a large water volume may drain out if a single cell located at the bottom of the system is occupied. Due to these effects, considerable outflow was computed for rainstorm amounts smaller than $30 \mathrm{~mm}$ in case of the smallest system size $(4 \times 10)$. Therefore, with decreasing size of the system, the threshold behaviour is less pronounced.

As shown in Fig. 6, the difference between the minimum and maximum of the modelled realizations increases with in- creasing rainstorm amount for small lattices with a coordination number $n=3.2$. Comparing the results of a system size $20 \times 50$ for the two coordination numbers 3.2 and 6.4 reveals that the realizations with minimum and maximum outflows have the same slope in the case of the high coordination number. In the case of limited connectivity, occupied clusters may be isolated and can not drain in down slope direction. For a few realizations, the computed outflow is very small due to the fact that some sites are isolated and can not drain out. This variation is not caused by the limited number of sites but by the limited number of bonds in small system. For the largest system with $100 \times 250$ sites, this effect vanishes and minimum and maximum realizations are parallel. Obviously, in a large system, manifold connections exist and clusters that are partially isolated can still drain out.

\section{Controls on modelled outflow from the Panola exper- imental hillslope}

\subsection{Measured parameters}

To test the validity of percolation theory to model the hillslope outflow during rainstorm events, we used the data of 147 storm events observed on the hillslope trench site at the Panola Mountain Watershed in Georgia, USA. Outflow in the trench occurred for rainfall amounts higher than $55 \mathrm{~mm}$ (Tromp-van Meerveld and McDonnell, 2006a). For 123 events, the initial water content at $70 \mathrm{~cm}$ depth was measured and only this subset will be used for further analysis. The frequency distribution of the initial water contents in the subsoil 


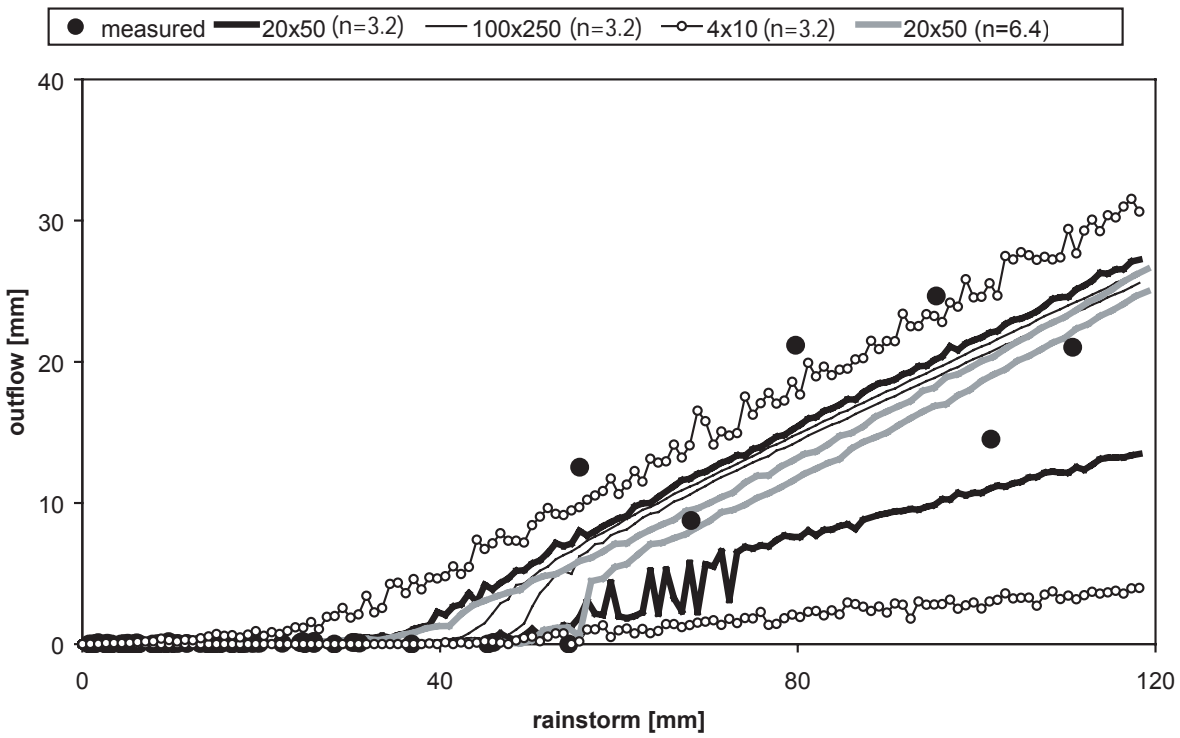

Fig. 6. Modelled outflow as a function of system size. The minimum and maximum of 100 realizations are compared with measurements (black symbols). The model indicated with thick black lines was fitted to the observed data $(\mu=30 \mathrm{~mm}, \sigma=17.6 \mathrm{~mm}, n=3.2, b=65 \%)$. The range between maximum and minimum values decreases with the size of the system. For comparison, a model with doubled coordination number ( $\mu=45 \mathrm{~mm}, \sigma=26 \mathrm{~mm}, n=6.4, b=65 \%$ ) is shown, where the minimum and maximum are in parallel for high rainstorm amounts. This is not the case for small systems with $n=3.2$.

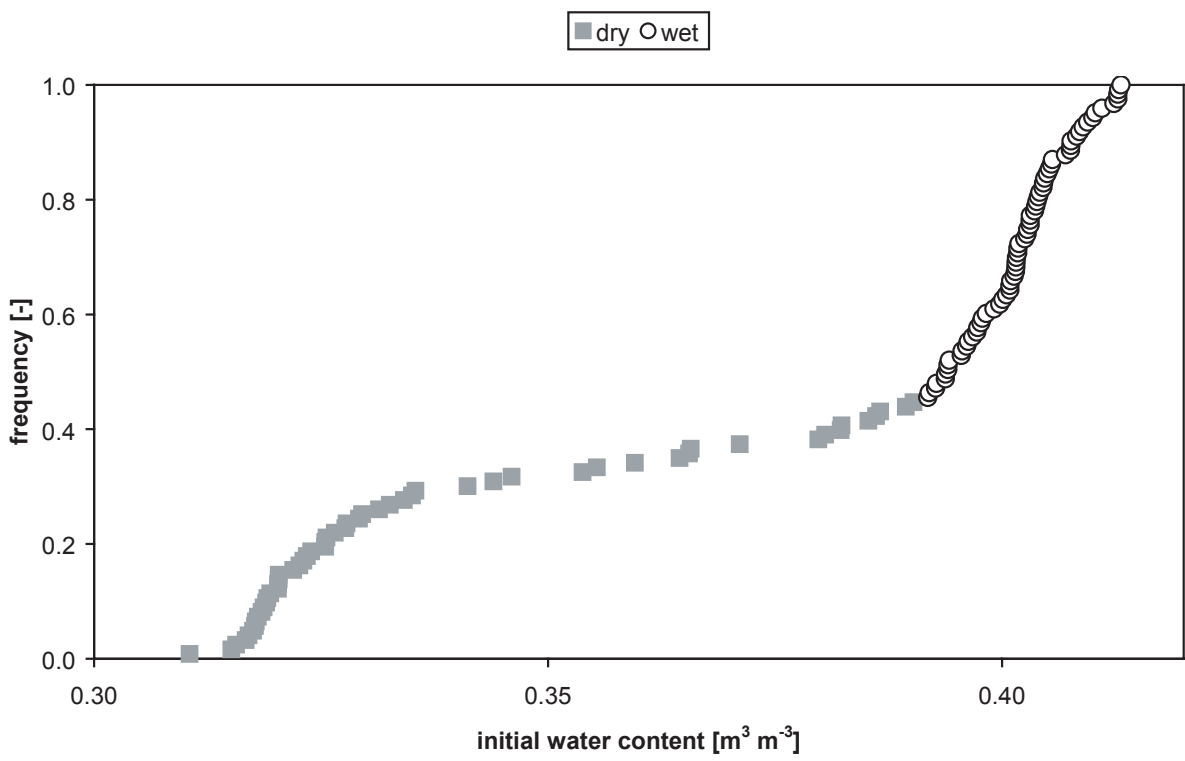

Fig. 7. Antecedent initial water content at Panola (Georgia, USA). The distribution of the initial water content before the rainstorm events measured at $70 \mathrm{~cm}$ is shown. Two classes of initial water content are defined. The threshold value between the "dry" (grey squares) and the "wet" (open circles) condition was chosen as $0.391 \mathrm{~m}^{3} \mathrm{~m}^{-3}$.

is shown in Fig. 7. Half of the values of initial water content $\theta$ are in a narrow range between 0.392 and $0.413 \mathrm{~m}^{3} \mathrm{~m}^{-3}$ with a mean value of $\theta_{w}=0.402 \mathrm{~m}^{3} \mathrm{~m}^{-3}$. With percolation theory, we want to model the outflow from similar systems for different rainfall amounts. A system with dry and wet initial conditions will probably not respond in the same way, because the overall storage capacity is higher in the initially dry system. Therefore, in this first subsection, we focus on the 68 rainstorm events with comparable high water content (wet class).

At the Panola hillslope soil type is uniform across the site and soil moisture is also uniform for the wet season (Tromp 


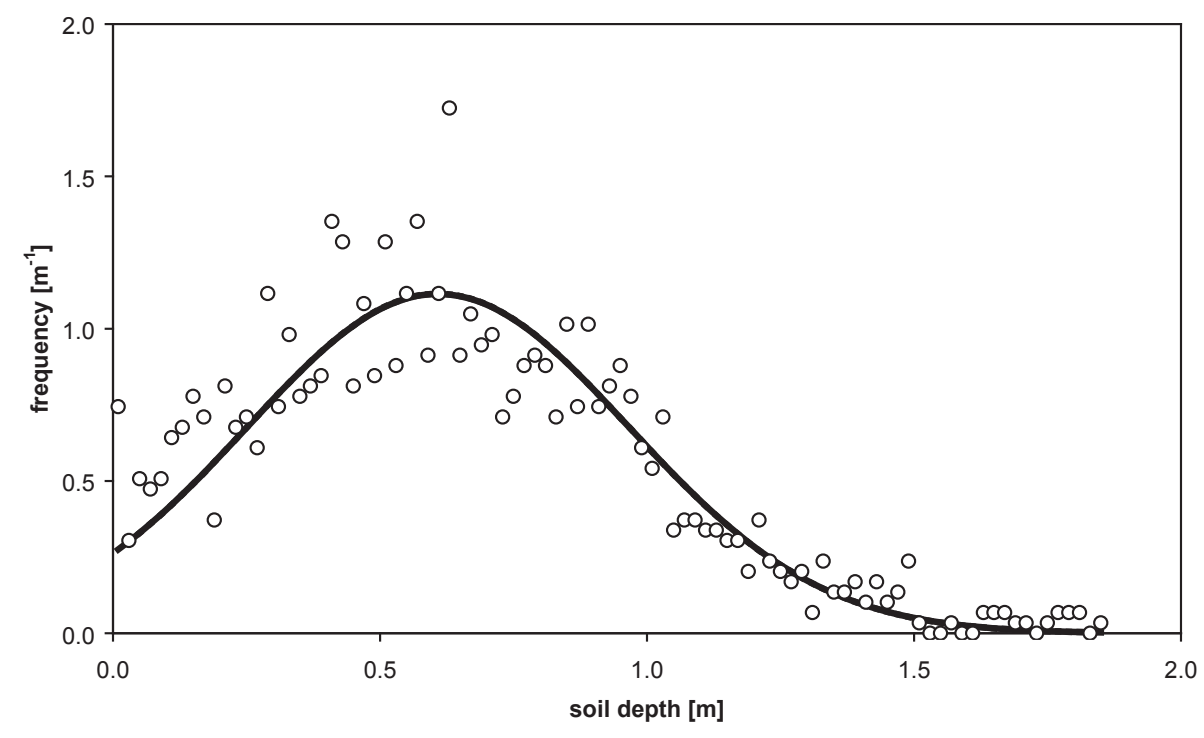

Fig. 8. Soil depth distribution at Panola (Georgia, USA). The measured distribution of soil depth was fitted with a normal distribution function. The mean of the fitted distribution is $0.609 \mathrm{~m}$ with a standard deviation of $0.358 \mathrm{~m}$. The coefficient of variation was used for the storage capacity distribution function as well.

van Meerveld, 2006c). Soil depth and bedrock profile are highly variable across the hillslope. The bedrock topography affects the flow paths because it is possible that water flow is restricted if the bedrock elevation increases in down slope direction. Such a configuration exists in a bedrock depression that was in fact a dominant factor at Panola (Tromp van Meerveld, 2006b). These local bedrock highs are modelled as decreased connectivity. A site without connection to a down slope site can be interpreted as such a configuration. For this reason, the connectivity expressed as coordination number was not set to 8.0 as for the standard orthogonal lattice but was determined by fitting and relates therefore to bedrock topography (Sect. 4.2). The soil depth determines the total moisture deficit (Tromp-van Meerveld and McDonnell, 2006c). At Panola, the soil depth distribution was measured on a grid spacing of $2 \mathrm{~m}$ (Freer et al., 1997). The integral of a Normal distribution function was fitted to the cumulative distribution function of the measured values with a mean soil depth $\mu_{d}$ of $0.609 \mathrm{~m}$ and a standard deviation $\sigma_{d}$ of $0.358 \mathrm{~m}$. In Fig. 8, the measured frequency distribution and the truncated normal distribution are shown. The coefficient of variation, $\sigma_{d} / \mu_{d}$ equals $58.8 \%$. Due to the fact that the soil depth determines the moisture deficit, we chose the same coefficient of variation for the storage capacity values.

Another property that must be taken into account is the effect of rainstorm intensity on subsurface flow. In Fig. 9a, the measured outflow as a function of maximum rainstorm intensity (amount of rainfall measured during a one hour interval) is shown. The rainstorm amount was higher than the threshold of $55 \mathrm{~mm}$ in only six of the 68 rainstorm events with wet initial conditions. As can be seen in Fig. 9a, the 62 rainstorm events with negligible outflow correspond to inten- sities ranging from 0.3 to $22.6 \mathrm{~mm} \mathrm{hr}^{-1}$. For the six events above the threshold, the outflow increases linearly with the maximum intensity. This may be explained by a time limitation of flow into the bedrock. For high rainstorm intensities, water flowed rapidly downwards before it could percolate into the bedrock. This effect of increased lateral flow is more relevant than the increase of the pressure head caused by the raising water table that would enhance the water flow into the bedrock. This hypothesis is confirmed by a sprinkling experiment of Tromp-van Meerveld et al. (2007). Alternatively, the enhanced runoff can be explained by an incomplete filling of the soil profile due to fast lateral water flow through macropores after intense rainstorm events. The influence of the intensity is explained in more detail in Fig. 9b. For two comparable rainstorm events with $r=95$ and $102 \mathrm{~mm}$, respectively, the maximum intensity was 22.4 and $5.6 \mathrm{~mm} \mathrm{~h}^{-1}$ and the outflow was 24.7 and $14.5 \mathrm{~mm}$, respectively. Obviously, the threshold is determined by the rainstorm amount but the volume of the subsurface flow is affected by the intensity as well. Based on these findings, we adapted the percolation model in a way that the outflow can be different for the same rainstorm intensity. For that purpose, the drainage parameter $b$ that determines the loss of free water to the bedrock, is not constant but varies within a certain range.

\subsection{Modeled subsurface flow for wet initial conditions}

We calculated the outflow with percolation theory for systems differing in size, loss of free water to the bedrock, connectivity (coordination number) and capacity distributions. According to the shape of the trench site, the ratio of upslope distance $\left(L_{y}\right)$ to the length of the trench $\left(L_{x}\right)$ was 2.5 , 


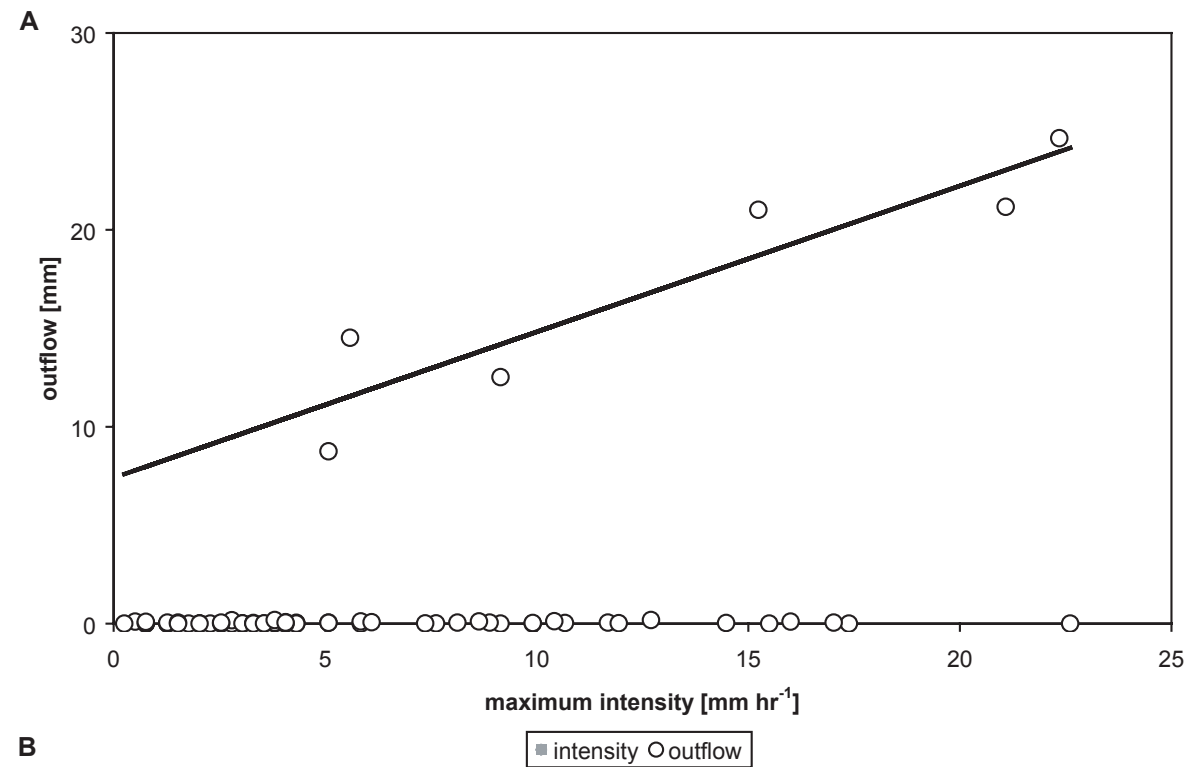

B

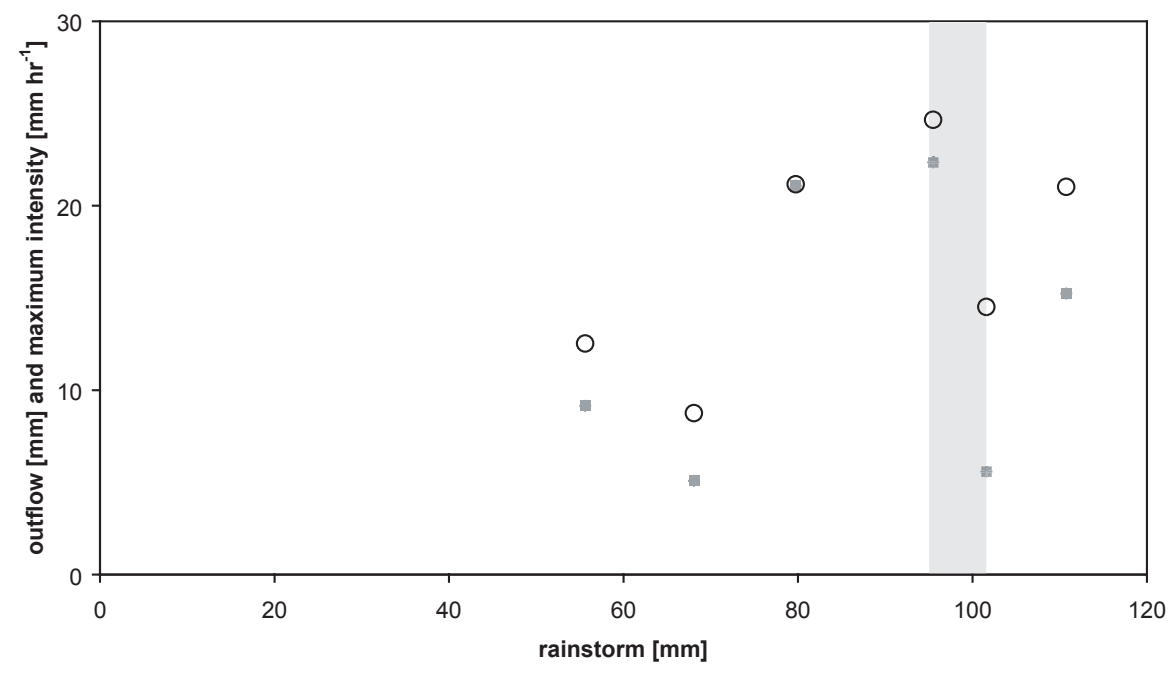

Fig. 9. Effect of rainstorm intensity at Panola. (A) For conditions exceeding the threshold, outflow increases linearly with maximum intensity (captured during one hour intervals). The symbols at the bottom line represent the storm events with negligible outflow. (B) The outflow (circles) as a function of rainstorm amount is affected by the variations of intensity (squares). Two events with rainstorm amount of about $100 \mathrm{~mm}$ but different intensities are indicated with a gray rectangle. The analysis was carried out for 68 events with wet initial conditions.

corresponding to the horizontal and vertical extensions of 20 and $50 \mathrm{~m}$, respectively. To find an optimized model, we changed the loss of free water to bedrock from $b=0.55$ to 0.75 in intervals of 0.05 , the mean of the storage capacity function from $\mu=20 \mathrm{~mm}$ to $50 \mathrm{~mm}$ in intervals of $5 \mathrm{~mm}$ and the coordination number from $n=1.6$ to 8.0 in intervals of 0.8 . For the resulting set with 315 parameter combinations, 100 realizations of systems with $20 \times 50$ sites were analyzed. The standard deviation was set to $58.8 \%$ of the mean capacity value, according to the coefficient of variation of the measured soil depth distribution. For each realization, a random network of bonds was generated. Then, for each of the measured 68 rainstorm amounts $r$, the storage capacities were distributed randomly in space and the resulting distribution of occupied sites and the outflow at the lower boundary was computed. For each of the 68 rainstorm amounts, the average of 100 realizations was compared to the measured subsurface flow. The squared difference between the measured outflow and the average of 100 realizations was summarized for the 68 rainstorm values. For the 315 combinations, the squared difference ranged between $207 \mathrm{~mm}^{2}$ and $1884 \mathrm{~mm}^{2}$. The smallest error was found for $\mu=30 \mathrm{~mm}, b=0.65$ and a coordination number of $n=3$.2. Two other combinations with $b=0.65$ ( $\mu=35 \mathrm{~mm}, n=4.0$ and $\mu=40 \mathrm{~mm}, n=4.8)$ were comparable with an error of $217 \mathrm{~mm}^{2}$ and $221 \mathrm{~mm}^{2}$. The same analysis of the parameter space was carried out for system 
Table 2. Parameters of model fitted to measured data. The cumulated quadratic difference between the 68 measured and modelled outflow values is given in bold. The values of the best three fits are given.

\begin{tabular}{cccccccc}
\hline & & & & & \multicolumn{3}{c}{$L_{x} \times L_{y}$} \\
$n$ & $\mu$ & $b$ & $p_{c}$ & $r_{c}$ & $10 \times 25$ & $20 \times 50$ & $40 \times 100$ \\
\hline 3.2 & $30 \mathrm{~mm}$ & 0.65 & 0.825 & $46.5 \mathrm{~mm}$ & $\mathbf{2 1 8}$ & $\mathbf{2 0 7}$ & $\mathbf{2 0 4}$ \\
4.0 & $35 \mathrm{~mm}$ & 0.65 & 0.705 & $46.0 \mathrm{~mm}$ & $\mathbf{2 1 7}$ & $\mathbf{2 1 7}$ & $\mathbf{2 1 7}$ \\
4.8 & $40 \mathrm{~mm}$ & 0.65 & 0.625 & $47.5 \mathrm{~mm}$ & $\mathbf{2 2 3}$ & $\mathbf{2 2 1}$ & $\mathbf{2 1 9}$ \\
\hline
\end{tabular}

sizes $10 \times 25$ and $40 \times 100$ and the same three combinations were optimal. The errors and parameters for the best combinations are given in Table 2. For the three combinations of parameters, the threshold amount of rainstorm $r_{c}$ was between 46.0 and $47.5 \mathrm{~mm}$. For this rainstorm amount, the occupation probability for the corresponding storage capacity distribution is equal to the percolation threshold. The percolation threshold for these percolation models equals 0.825 , 0.705 and 0.625 for coordination numbers of $n=3.2,4.0$ and 4.8 , respectively. The spatial and temporal patterns of localized water tables analyzed by Tromp-van Meerveld and McDonnell (2006b) indicate that a fraction of about 0.60 and 0.65 of their measuring sites must have a water table to produce subsurface flow. These fractions are therefore in the same order of magnitude as the modelled percolation thresholds.

The difference between the modelled threshold of about $47 \mathrm{~mm}$ and the experimentally determined value of $55 \mathrm{~mm}$ may be explained by the variability of the outflow for systems with limited size. For a limited number of realizations, it is possible that no outflow occurs even for a rainstorm amount above the threshold. For that purpose, we focus in the following on the variability of the modelled outflow based on the best fit with $\mu=30 \mathrm{~mm}, n=3.2$ and $b=0.65$. The results of this model are shown in Figs. 5 and 6. For the fitting, only the average of 100 realizations was analysed. The range of modelled outflow is given in Fig. 6. The minimum and maximum values of all realizations are compared to the measurements. The modelled variation is smaller than the range of observed values. As shown in Fig. 6, the variation increases with a decreasing number of nodes. For small systems, the threshold behaviour is less pronounced and high outflow values would be obtained for rainstorm amounts below $r_{c}=46.5 \mathrm{~mm}$. This was not observed at Panola and the measured variations must be caused by other effects. Alternatively, the influence of intensity on subsurface flow can be modelled by introducing a varying fraction of flow into the bedrock. For that purpose, we assume that the factor $b$ is not a constant but is chosen randomly for each rainstorm event. The range of the value is chosen based on 100 realizations with a system of size $20 \times 50$ for different factors $b$. To explain the measured range of outflow between 24.7 and
$14.5 \mathrm{~mm}$ (see Fig. 9b) for rainstorm events of 95 and $102 \mathrm{~mm}$, respectively, the factor $b$ must be within $0.65 \pm 0.15$. For $r=95 \mathrm{~mm}$ with $b=0.50$, the mean value of 100 realizations is $26.3 \mathrm{~mm}(>24.7 \mathrm{~mm})$ and the average for $r=102 \mathrm{~mm}$ with $b=0.80$ is $11.6 \mathrm{~mm}(<14.5 \mathrm{~mm})$. For that purpose, the loss of free water to the bedrock for each modelled rainstorm event was a random number between 0.50 and 0.80 . This corresponds to the subsurface stormflow runoff coefficient above the threshold of 30-80\% found by Tromp-van Meerveld and McDonnell (2006a). The range of modelled outflow is shown in Fig. 10. With this adaptation, the model describes the observed variations more accurate but the variability close to the threshold rainstorm amount is not yet modelled properly.

\subsection{Subsurface flow as a function of initial conditions}

Up to now, the storage capacity distribution function was the same for all realizations. For the 68 events analysed so far, the initial water content $\theta$ measured at $70 \mathrm{~cm}$ depth was between 0.392 to $0.413 \mathrm{~m}^{3} \mathrm{~m}^{-3}$. The storage capacity function was optimized for the mean water content of the 68 events with $\theta_{w}=0.402 \mathrm{~m}^{3} \mathrm{~m}^{-3}$. To relate the storage capacity $c$ to an initial water content $\theta$, we assume that the storage capacity equals $c=\left(\theta_{c}-\theta\right)(1000 d)$, with the threshold water content $\theta_{c}$ that must be achieved to have a free water table and the soil depth $d$ multiplied with 1000 to obtain a soil depth in mm. For $\theta=\theta_{w}=0.402 \mathrm{~m}^{3} \mathrm{~m}^{-3}$, the storage capacity values were given by a truncated normal distribution with $\mu=30 \mathrm{~mm}$ and a standard deviation of $17.6 \mathrm{~mm}$. For the mean values of the soil depth $\left(\mu_{d}=0.609 \mathrm{~m}\right)$ and storage capacity distribution function $(\mu=30 \mathrm{~mm})$, we obtain $\mu=\left(\theta_{c}-\theta_{w}\right) \mu_{d}$ with a resulting threshold water content of $\theta_{c}=1 / 1000 \mu / \mu_{d}+\theta_{w}=0.451 \mathrm{~m}^{3} \mathrm{~m}^{-3}$. With this threshold value, the storage capacity distribution function can be adapted to any initial water content with

$\mu(\theta)=\left(\theta_{c}-\theta\right) 1000 \mu_{d}=\mu+1000 \mu_{d}\left(\theta_{w}-\theta\right)$.

For a decrease of initial water content of $0.01 \mathrm{~m}^{3} \mathrm{~m}^{-3}$, the mean of the storage capacity is shifted from $30 \mathrm{~mm}$ to $36 \mathrm{~mm}$. For the 68 rainstorm events with wet initial conditions, the outflow was computed for 100 realizations of a system of size $20 \times 50(\Delta x=1 \mathrm{~m})$ with a coordination number $\mathrm{n}=3.2$, a loss to the bedrock between 0.50 and 0.80 , and a mean $\mu(\theta)$ and a standard deviation of $\sigma(\theta)=\sigma_{d} / \mu_{d} \mu(\theta)$ that depend on the initial water content.

The cumulated distribution function of the storage capacity values is equal for all initial water content $\theta$ for a storage capacity value of $c_{i}=0$

$$
\frac{1}{2}+\frac{1}{2} \operatorname{erf}\left[\frac{c_{i}-\mu(\theta)}{\sigma_{d} / \mu_{d} \mu(\theta) \sqrt{2}}\right]=\frac{1}{2}+\frac{1}{2} \operatorname{erf}\left[\frac{\mu_{d}}{\sigma_{d} \sqrt{2}}\right] .
$$

Based on Eq. (4), the fraction of sites with storage capacity 0 is the same as the fraction of sites with soil depth 0 . This identity is required because we interpret the fraction of sites 


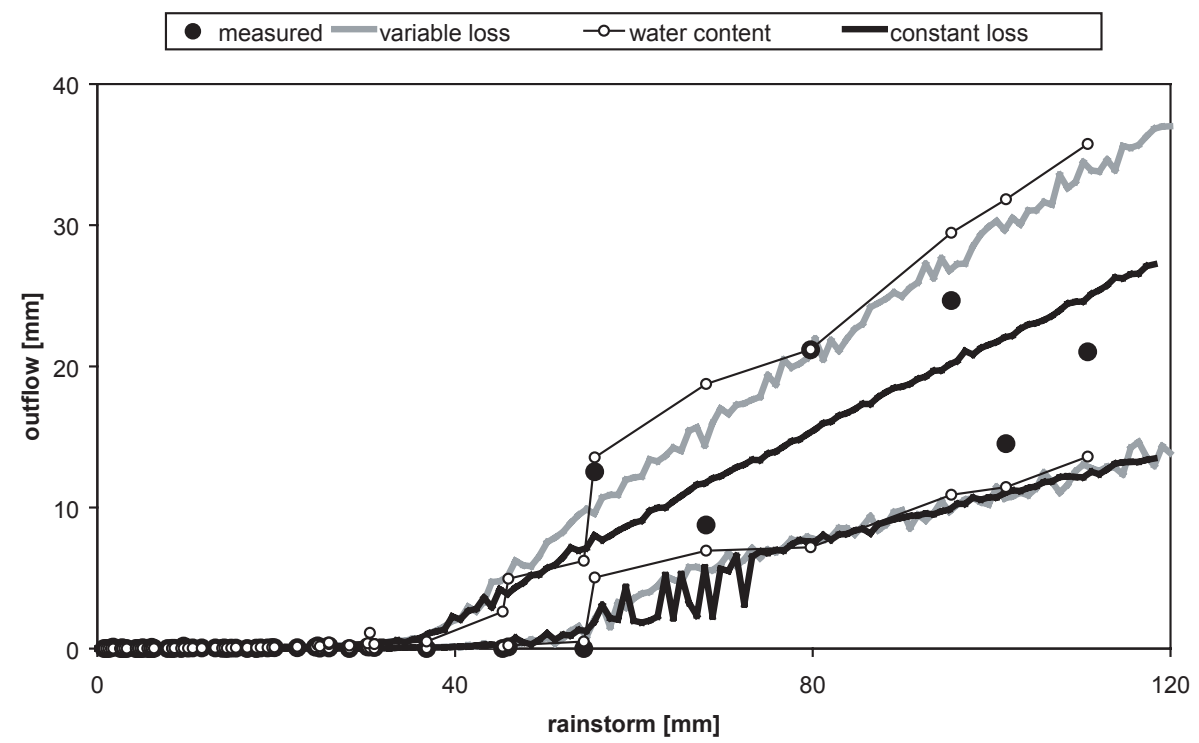

Fig. 10. Variability of subsurface flow. For 100 realizations of a system of size $20 \times 50$, the loss of free water varied between $50 \%$ and $80 \%$ (gray line). These results are compared to the measured values (black disks) and the model with a constant loss of $65 \%$ (bold black lines). In addition to the variable loss of free water, the capacity distribution was adapted to the initial water content of the 68 events with high initial water content between 0.392 and $0.413 \mathrm{~m}^{3} \mathrm{~m}^{-3}$ (black line with circles) by choosing the mean of the storage distribution as a function of the initial water content. The coordination number in all cases was equal to $n=3.2$.

with storage capacity 0 as bare bedrock and this does not depend on initial water content. The results are shown in Fig. 10. Now, the range of modelled outflow corresponds to the measured values.

The same adaptation of the storage capacity function to the initial water content was done for the 55 rainstorm events with initial water content $\theta$ between 0.311 and $0.390 \mathrm{~m}^{3}$ $\mathrm{m}^{-3}$. The response of hillslope to rainstorm may be different for dry and wet initial conditions. Sidle et al. (1995) and Tromp-van Meerveld and McDonnell (2006a) found that the contribution of soil pipes was reduced for dry initial conditions. For dry initial conditions, less water is in the system and the storage capacity is increased. For each event, 100 realizations of a system of size $20 \times 50(\Delta x=1 \mathrm{~m})$ with a coordination number $\mathrm{n}=3.2$, a loss to the bedrock between $b=0.50$ and 0.80 and a mean $\mu(\theta)$ and a standard deviation of $\sigma(\theta)=\sigma_{d} / \mu_{d} \mu(\theta)$ of the storage capacity were analysed. There was only one rainstorm event (on 26 April 1997 with a total rainfall amount of $87.9 \mathrm{~mm}$, maximum intensity $27.7 \mathrm{~mm} \mathrm{hr}^{-1}$, an initial water content of $0.387 \mathrm{~m}^{3} \mathrm{~m}^{-3}$ and an outflow of $5.1 \mathrm{~mm}$ ) that was not within the modeled range. This deviation can be explained by the preceding period of 60 days without intense rainstorm event. In this situation, the topsoil was probably much drier than the soil in $70 \mathrm{~cm}$ depth and the water deficit was underestimated. We could model this single event by reducing the system size to $10 \times 25$ with a distance of $\Delta x=2 \mathrm{~m}$ between two grid points. The maximum and minimum values for a system of size $10 \times 25(\Delta x=2 \mathrm{~m})$ are shown in Fig. 11. By adapting the storage capacity ac- cording to the measured initial water content, it is possible to derive the range of subsurface outflow for dry initial conditions from the model optimized for wet initial conditions. For the 123 rainstorm events analyzed in this study, the mean storage capacity ranged from $23 \mathrm{~mm}$ for $\theta=0.413 \mathrm{~m}^{3} \mathrm{~m}^{-3}$ to $85 \mathrm{~mm}$ for $\theta=0.311 \mathrm{~m}^{3} \mathrm{~m}^{-3}$.

\section{Discussion}

Rainfall-induced subsurface stormflow at the hillslope scale is widely acknowledged as a dominant outflow process in many steep, humid watersheds (Bonell, 1998; Weiler et al., 2005). Despite recent efforts that have been made to classify and organize hillslope behaviour (Scherrer and Naef, 2002; Uchida et al., 2005) we are still unable to make nontrivial predictions about water flow pathways and processes on hillslopes in ungauged basins. One feature of hillslope behaviour in the experimental literature that is now evident is the rather common characteristic nonlinearity of the relationship between rainfall and subsurface stormflow. This threshold relationship has been argued as the main expression of emergent behaviour at the hillslope scale (McDonnell, 2003). The present work has explored the use of percolation theory to analyse the effects of hydrological properties on modelled outflow, and in particular, the relation between hillslope wetting pattern and the subsurface stormflow threshold. This pattern-process linkage has been noted as the key to conceptualization of this nonlinearity (Tromp-van Meerveld and McDonnell, 2006b). Our percolation approach 


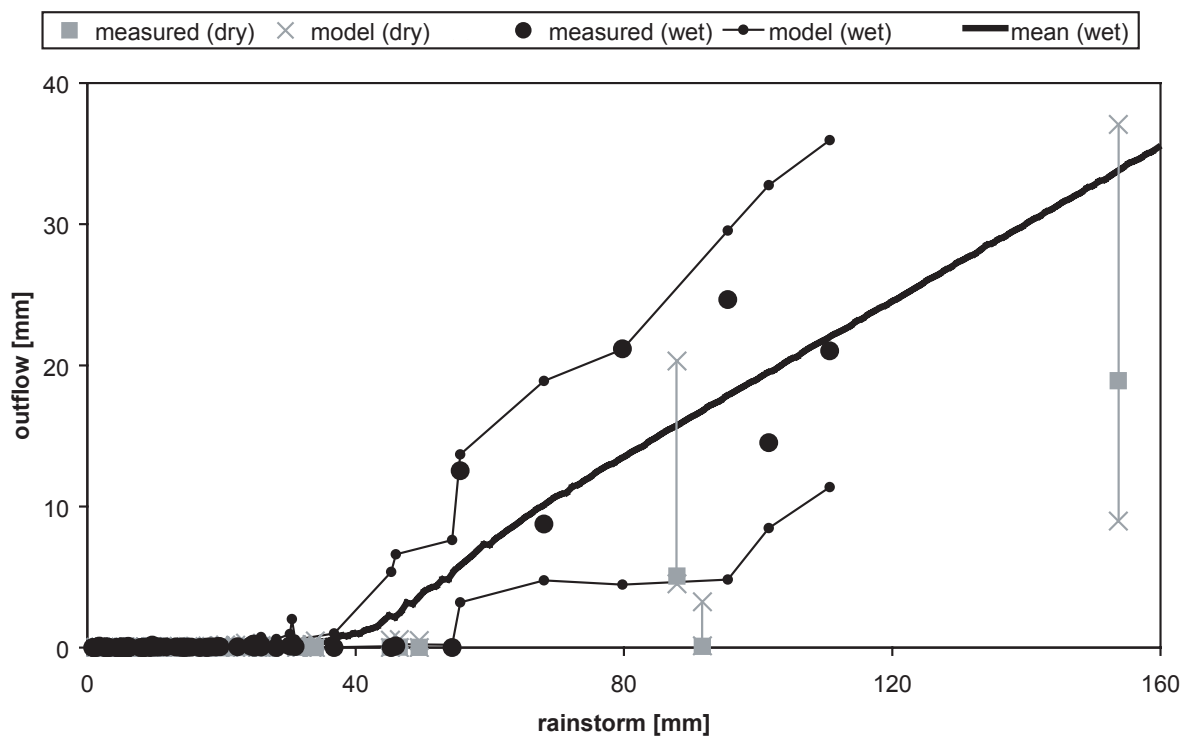

Fig. 11. Modelled outflow for wet and dry initial conditions. For each of the 68 and 55 events with wet (black disks) and dry (gray squares) initial conditions, respectively, 100 realizations of a system of size $10 \times 25$ were generated. The modelled results for the wet initial conditions are shown with a black line with symbols. The minimum and maximum values for the dry cases are indicated with gray crosses that are connected for some events to show the range of computed outflow. The capacity distributions were changed according to the initial water content. The loss of free water was between 50 and $80 \%$ and the coordination number was equal to $n=3.2$. For comparison, the averages for wet initial conditions are shown (black bold line) computed with a model of size $10 \times 25$ with $\mu=30 \mathrm{~mm}, \sigma=17.6 \mathrm{~mm}, n=3.2$ and $b=65 \%$.

was motivated by the observed spatial and temporal patterns of transient water saturation and the emergence of connectivity with increasing rainstorm amounts (see Fig. 1). We do not claim that this model approach describes all aspects of the subsurface flow threshold because it neglects the dynamics of water distribution during the rainstorm event and it does not represent all spatial properties of the hillslope. But percolation theory can quantify the connectivity and its relation to threshold phenomena, and in this respect it adds another dimension to conventional distributed hydrological model. It is also apparent that the water balance description of each site in the percolation network can be kept very simple requiring data on soil water storage, soil depth and bedrock drainage, but no detailed information on hydraulic soil properties are needed which conventional models often require.

\subsection{Assumptions in the percolation theory approach}

Our analyses completed in this paper are based upon the following underlying process assumptions:

(i) Each element in the model is in one of two possible states: with or without a transient water table. Water can flow downwards between sites with a water table.

(ii) The initial water content and thus the water deficit in the underlying substrate is important for the threshold value of subsurface flow initiation. For this reason, we modelled in a first step the outflow for conditions with similar water contents and adapted the model for dry conditions afterwards. (iii) In the model, water flow occurs if two occupied sites are connected. These connections can be interpreted in two different manners. Firstly, the connections may be macropores that enhance lateral flow when the connectedness of subsurface saturation is achieved. Secondly, water flow along the bedrock in down slope direction is only possible if the bedrock elevation decreases in down slope direction (e.g. connected bedrock hollows). Therefore, a connection corresponds to a configuration fulfilling this condition.

(iv) The factors influencing subsurface stormflow initiation are randomly distributed. Various soil characteristics are relevant for the response to a rainstorm. At Panola the soil depth, which is close to normally distributed, determines the moisture deficit and storage capacity. While any type of distribution can be easily taken into account with the percolation model, this study was restricted to the assumption of a normal distribution.

\subsection{Ability to replicate Panola behavior}

To reproduce the outflow measured at the Panola trench site we adapted the following parameters of the model:

(i) We used a normal distribution for the storage capacity with mean $30 \mathrm{~mm}$ and standard deviation of $17.6 \mathrm{~mm}$. For an initial water content of $0.402 \mathrm{~m}^{3} \mathrm{~m}^{-3}$ and a mean soil depth of $0.609 \mathrm{~m}$, this corresponds to an increase of the water content to a value of $0.451 \mathrm{~m}^{3} \mathrm{~m}^{-3}$.

(ii) For a rainstorm amount of 46.0 to $47.5 \mathrm{~mm}$, the percolation threshold is reached and the outflow increases. This 
corresponds to a fraction of sites with a water table between 0.625 and 0.825 .

(iii) The bedrock can not be described as an impermeable boundary. It dominates the slope of the relationship between subsurface outflow and rainstorm amount for rainfall higher than the threshold $r_{c}$. In addition, the loss to the bedrock depends on the intensity of the rainstorm and varied between 0.5 and 0.8 .

(iv) The size of the system was $20 \times 50$ sites, corresponding to $20 \mathrm{~m} \times 50 \mathrm{~m}$. In a special case (after a long dry period), the system size had to be reduced $(10 \times 25)$ to reproduce an experiment with high rainstorm amount and small outflow. So, the distance between two sites $\Delta x$ is about $1-2 \mathrm{~m}$. This can be interpreted as the length of a soil pipe connecting sites with free water.

(v) The coordination number affects the increase of subsurface flow close to the threshold and the variability of modeled outflow values. With decreasing coordination number, the variability of modelled outflow values increases. For higher coordination numbers, the variations of modeled subsurface flow would be too small to explain the observed variability. In the percolation model, the best results were found for a coordination number of 3.2 .

(vi) For dry initial conditions, a rainstorm amount close to the threshold value determined for wet initial conditions does not initiate subsurface flow. Due to the increased water deficit, more rainstorm water is needed. We could estimate the range of expected outflow values for dry initial conditions with the percolation model.

While the percolation model can reproduce various aspects of the Panola hillslope, it is not intended to be a physically based hydrological model that provides a detailed description of small scale hillslope processes. We acknowledge that at this stage the parameters used here such as the coordination number may lack physical basis, however, we believe that the modelling concept is ideally suited for systems in which connectivity is an essential system property. Processes that may affect the hillslope outflow not considered in this model include the distribution of rainfall water as a dynamic process resulting in lateral flow into sites without a free water table. In addition, the water flow along the bedrock is affected by large scale heterogeneities and the correlation length of the bedrock profile. As shown in Trompvan Meerveld and McDonnell (2006a) the water flows preferentially out from a valley in the bedrock. Such large scale structures are not reproduced in the model because it is based on limited spatial information. Finally, the shown application of the model for conditions with dry initial conditions may be too simplified because it is based on the assumption of constant water content in the profile. Probably, the filling of the whole profile water must be described in more detail to enhance the predictions.

\subsection{Percolation theory for prediction}

We conclude the analysis of the percolation model with the discussion about its application to prediction of ungauged and gauged basins.

In the case with detailed observation, a first application is the analysis of measured subsurface flow. With the percolation model approach presented in this paper, we can characterize a system based on the measured rainstorm response. An interpretation of a measured response with the percolation model gives us the means to quantitatively evaluate process assumptions e.g. the role of bedrock permeability and the temporal distribution of initial water content. In case of several measured outflow values with similar rainstorm amount along with some information about the presence of soil pipes, the connectivity, the size of the characteristic soil units and the distribution function of the storage capacity values can be deduced from the measured outflow. So, with the percolation model the subsurface outflow response to the rainstorm amount could be used to classify different hillslopes. This kind of classification could be compared or combined with the methods described by Scherrer and Naef (2002) and Uchida et al. (2005).

The situation is different when little data is present and lack of resources does not permit us to monitor hillslopes in the detail as done at the Panola site. The key to answering the question of how percolation theory could be applied is to decide what observation can we use to parameterize the model other than the detailed monitoring and measurements of water table, depth to bedrock etc. As connectivity is the focus of applying percolation theory, we suggest that spatiotemporal measurements probing saturation in the subsurface may provide such an observational window. Current methods of monitoring soil moisture in space and time such as ground penetrating radar, electromagnetic surveys and electrical resistivity tomography may provide us with the required information (Holden, 2004). How this can be used to parameterize a percolation model is left for future research, but it is important to emphasize that percolation theory may be one approach to using patterns in space and time for analyzing subsurface flow in response to rainfall.

\section{Summary and conclusions}

The hillslope outflow response to a rainstorm event is highly nonlinear. This behaviour is caused by the random distribution of soil properties. We used percolation theory to model the effect of randomly distributed soil properties on subsurface flow. The property that was distributed was denoted as storage capacity, the water volume per cross-section that is retained before free water is available. The capacity depends on soil thickness, porosity (or field capacity) and initial water content. Free water can flow into the trench at the bottom, if a continuous system of sites with free water exists. 
The modelled response depends on the moisture deficit, the number of connections, the loss of free water to the permeable bedrock and the size of the system. We found that the Panola trench site could be described by a percolation model of bedrock loss of about $65 \%$, a connectivity of 3.2, a normal distribution of the capacity values with mean $30 \mathrm{~mm}$ and standard deviation $17.6 \mathrm{~mm}$ and a size of the sites of $1-2 \mathrm{~m}$.

To compare the model with the experimental data, 123 events with measured rainstorm amount, outflow and initial water content at $70 \mathrm{~cm}$ were analysed. The data set was subdivided into two classes, one set with 68 measurements with comparable water content of about $0.402 \mathrm{~m}^{3} \mathrm{~m}^{-3}$ and a second set with 55 rainstorm events for water contents between 0.311 and $0.391 \mathrm{~m}^{3} \mathrm{~m}^{-3}$. In the second case, we assumed that the rather dry soil has to collect more water before it behaved like the soil in the first data set. So, the mean of the storage capacity was increased depending on the initial water content and the outflow could be modelled with the same percolation model. From this finding we conclude that percolation theory and the underlying assumption of randomly distributed soil properties is a valid approach to describe and quantify threshold processes controlling the hillslope outflow after rainstorm events. The percolation model presented in this paper is focussed on elucidating the role of flow path connectivity on hillslope outflow which implies that in its current state it is not meant to be used for time series predictions of rainfall-runoff processes at the hillslope scale.

Acknowledgements. We would like to thank J. Peters and the USGS Atlanta District office for their ongoing work at Panola and the Panola Mountain State Park for their ongoing logistical support. This work was partly funded by NSF grant EAR-0196381.

Edited by: G. Hancock

\section{References}

Berkowitz, B. and Ewing, R. P.: Percolation theory and network modeling - applications in soil physics, Surveys in Geophysics, 19, 23-72, 1998.

Berkowitz, B. and Balberg, I.: Percolation theory and its application to groundwater hydrology, Water Resources Research, 29(4), 775-794, 1993.

Bonell, M.: Selected challenges in outflow generation research in forests from the hillslope to headwater drainage basin scale, Journal of the American Water Resources Association, 34(4), 765785, 1998.

Broadbent, S. R. and Hammersley, J. M.: Percolation Processes I. Crystals and Mazes, Proceedings of the Cambridge Philosophical Society, 53(3), 629-641, 1957.

Burns, D. A., Hooper, R. P., McDonnell, J. J., Freer, J. E., Kendall, C., and Beven, K.: Base cation concentrations in subsurface flow from a forested hillslope: The role of flushing frequency, Water Resources Research, 34, 3535-3544, 1998.

Essam, J. W.: Percolation theory, Reports on Progress in Physics, 43, 833-912, 1980.
Freer, J., McDonnell, J. J., Beven, K. J., Brammer, D., Burns, D., Hooper, R. P., and Kendall, C.: Topographic controls on subsurface storm flow at the hillslope scale for two hydrologically distinct small catchments, Hydrological Processes, 11, 1347-1352, 1997.

Freer, J., McDonnell, J. J., Beven, K. J., Peters, N. E., Burns, D. A., Hopper, R. P., Aulenbach, B., and Kendall, C.: The role of bedrock topography on subsurface storm flow, Water Resources Research, 38(12), 1269, doi:10.1029/2001WR000872, 2002.

Holden, J.: Hydrological connectivity of soil pipes determined by ground-penetrating radar tracer detection, Earth Surface Processes and Landforms, 29, 437-442, 2004.

Hunt, A. G.: Percolation theory for flow and transport in porous media, Lecture Notes in Physics, 674, Springer, Berlin, 2005.

Kirkby, M. J.: Hillslope runoff process and models, J. Hydrol., 100, 315-339, 1988.

McDonnell, J. J.: Where does water go when it rains? Moving beyond the variable source area concept of rainfall-outflow response, Hydrological Processes, 17(2) 1869-1875, 2003.

Mosley, M. P.: Streamflow generation in a forested watershed, Water Resour. Res., 15, 795-806, 1979.

Sahimi, M.: Applications of Percolation Theory, Taylor and Francis, London, 1994.

Scherrer, S. and Naef, F.: Decision scheme to indicate dominant hydrological flow processes on temperate grassland, Hydrological Processes, 17(2), 391-401, 2003.

Sidle, R. C., Tsuoyama, Y., Noguchi, S., Hosoda, I., Fujieda, M., and Shimizu, T.: Introduction to seasonal hydrologic response at various spatial scales in a small forested catchment, Hitachi Ohta, Japan, J. Hydrol., 168, 227-250, 1995.

Sidle, R. C., Noguchi, S., Tsuboyama, Y., and Laursen, K.: A conceptual model of preferential flow systems in forested hillslopes: evidence of self organization, Hydrological Processes, 15, 16751692, 2001.

Spence, C. and Woo, M.-K.: Hydrology of subarctic Canadian shield: soil-filled valleys, J. Hydrol., 279, 151-156, 2003.

Stauffer, D. and Aharony, A.: Introduction to Percolation Theory, 2nd edition, Taylor and Francis, London (second printing), 1994.

Tani, M.: Outflow generation processes estimated from hydrological observations on a steep forested hillslope with a thin soil layer, J. Hydrol., 200, 84-109, 1997.

Tromp-van Meerveld, H. J. and McDonnell, J. J.: Threshold relations in subsurface stormflow 1. A 147 storm analysis of the Panola hillslope, Water Resources Research, 42, W02410, doi:10.1029/2004WR003778, 2006a.

Tromp-van Meerveld, H. J. and McDonnell, J. J.: Threshold relations in subsurface stormflow 2. The fill and spill hypothesis, Water Resources Research, 42, W02411, doi:10.1029/2004WR003800, 2006b.

Tromp-van Meerveld, H. J. and McDonnell, J. J.: On the interrelations between topography, soil depth, soil moisture, transpiration rates and species distribution at the hillslope scale, Advances in Water Resources, 29, 293-310, 2006c.

Tromp-van Meerveld, H. J., Peters, N. E., and McDonnell, J. J.: Effect of bedrock permeability on subsurface stormflow and the water balance of a trenched hillslope at the Panola Mountain Research Watershed, Georgia, USA, Hydrol. Processes, 21, 750769, 2007.

Uchida, T., Kosugi, K., and Mizuyama, T.: Outflow characteristics 
of pipeflow on rainfall-outflow phenomena in mountainous watershed, J. Hydrol., 222, 18-36, 1999.

Uchida, T., Tromp-van Meerveld, I., and McDonnell, J.: The role of lateral pipe flow in hillslope outflow response: an intercomparison of non-linear hillslope response, J. Hydrol., 311, 117-133, 2005.

Weiler, M., McDonnell, J., Tromp-van Meerveld, I., and Uchida, T.: Subsurface stormflow, Encyclopedia of Hydrological Sciences, Wiley and Sons, 2005.
Weiler, M., Uchida, T., and McDonnell, J.: Connectivity due to preferential flow controls water flow and solute transport at the hillslope scale, Proceedings of MODSIM 2003, Townsville, Australia, 2003.

Western, A. W., Blöschl, G., and Grayson, R. B.: Towards capturing hydrologically significant connectivity in spatial patterns, Water Resources Research, 37(1), 83-97, 2001.

Whipkey, R. Z.: Subsurface stormflow from forested slopes, Bulletin of the International Association of Scientific Hydrology, 10, 74-85, 1965. 